\title{
Suspended particulate matter and health: new light on an old problem
}

\author{
R L Maynard, R E Waller
}

Forty years ago the Clean Air Act 1956 paved the way for the elimination of the main component of suspended particulate matter (SPM), the coal smoke that had plagued urban areas of the United Kingdom for centuries. ${ }^{1}$ The process was to be a gradual one, particularly in relation to domestic sources, and it was anticipated that it might take more than 20 years to clear the air in all the areas that had been heavily polluted. In the event, aided by the growing popularity of gas, oil and electricity for home heating purposes, the task was largely completed by the late 1960s. The switch to these fuels, rather than to the solid smokeless fuels that were being promoted initially, led to a marked reduction in concentrations of sulphur dioxide as well as those of smoke. It appeared then that acute effects of these pollutants on health - such as sudden increases in mortality, hospital admissions, or exacerbations of bronchitis - were no longer discernible. ${ }^{2}$

Since then the scene has changed substantially, however, with intense interest generated again over the past 10 years in relationships between particles in the air and acute effects on health. A large number of publications have appeared, some based on re-analyses of older data from the United Kingdom, ${ }^{3}$ and others resulting from new research initiatives, mainly in the United States. ${ }^{4-6}$ This does not mean that there has been a return to the clearly defined adverse effects of the 1950s and 1960s. When considered in a time-series manner, the day-to-day fluctuations in the various health indices now represent little more than "noise" on the major signals related to seasonal, weather, and infective agents. To isolate such small effects of pollution is a difficult task and to determine any specific role for particles - rather than that of sulphur dioxide or other air pollutants such as ozone or nitrogen dioxide that have been linked with health effects in recent years ${ }^{\bar{T}}-$ has called for the development of improved statistical computing techniques capable of handling the huge databases involved when daily data on a wide range of variables over a number of years are being examined.

The outcome of this renewed surge of activity over the past 10 years has been the demonstration of a consistent statistical association between a range of adverse effects on health and concentrations of suspended particulate matter in the air, extending down to the low concentrations that are common today. While there had never been a specific assumption of a threshold in earlier assessments, ${ }^{8}$ "lowest observed adverse effect levels" had been defined and used as a basis for guidelines and standards for the protection of public health. The approach now used by the World Health Organisation ${ }^{9}$ in respect of suspended particulate matter is to determine the percentage increase in health indicators such as daily mortality or admissions to hospital which correspond with a given rise in the concentration of particles. This leaves national authorities with the task, not only of considering whether the statistical relationships should be treated as causal, but also of assessing what level of potential risk to the public might be acceptable. If the relationships are truly continuous and non-threshold, zero risk is not an option since there are natural sources of particulate matter that contribute to background concentrations.

In the United States, with a revision of national air quality standards for particulate matter pending, the Health Effects Institute (HEI) has been commissioned to examine the integrity of the many studies of relationships with daily mortality that have now been reported. They have been able to obtain the original data for a number of them and rework the analyses, looking carefully at the question of whether the associations with health are more clearly related to particulate matter than to other monitored pollutants or to other factors such as temperature. In their first report ${ }^{10}$ they conclude that the findings of the original researchers are reproducible, pointing principally to a role for suspended particulate matter though with a little uncertainty in some instances about the relative importance of that or of associated pollutants such as sulphur dioxide. At this stage the HEI has not aimed to determine whether the associations are causal and in the next phase closer scrutiny will be given to "harvesting" effects (the extent to which increases in air pollution bring forward the deaths of severely ill people by a few days or weeks, rather than affecting annual death rates appreciably), to temperature effects, and to errors in exposure estimates. It is made clear that, at this stage, the HEI team is examining the validity of the databases and of the analytical procedures rather than trying to determine whether the associations are causal.

A wide ranging review of the effects of particles on health has been published recently in the United Kingdom. ${ }^{11}$ This covers the nature of suspended particulate matter, questions of dosimetry and the toxicology of inhaled particles, findings from controlled inhalation studies, and a close examination of epidemiological investigations. In contrast with the situation for other air pollutants, one of the basic problems is that suspended particulate matter is not a defined entity. It includes finely divided carbonaceous material derived from the incomplete combustion of hydrocarbon fuels (notably from coal fires in earlier decades but now mainly from diesel engines), inorganic dusts dispersed from industrial processes, and secondary particles such as sulphates and nitrates formed by reactions between gases in the atmosphere. To some extent it is characterised by the monitoring method adopted; the traditional "black smoke" method as used in the United Kingdom responds principally to the carbon content whereas gravimetric methods assess the total suspended particulate concentration irrespective of composition. The latter can, however, include relatively large particles of limited relevance to health but having a disproportionate effect on the mass of material. The preferred option in recent years has been a gravimetric assessment limited to particles having equivalent aerodynamic diameters of less than 10 $\mu \mathrm{m}\left(\mathrm{PM}_{10}\right)$. This does not represent any new or specific type of material but encompasses the smoke or secondary particles that have always been present and its composition 
varies with the nature of the sources contributing to the aerosols at any given place and time.

The variable composition of suspended particulate matter makes it difficult to conduct focused toxicological studies and much of the work that has been reported ${ }^{12}$ relates to individual components such as sulphates or sulphuric acid. In mass terms the amount of material inhaled at prevailing levels of particles in the air is small, and it is difficult to explain the types of effects indicated from epidemiological findings in classical toxicological terms. Some recent work ${ }^{13}$ has indicated a possible role for ultrafine particles with diameters of less than $50 \mathrm{~nm}(0.05 \mu \mathrm{m})$, and it may be that respiratory responses are influenced more by surface area or number concentration than by the mass concentration of particles.

The rapidly expanding literature on epidemiological studies of associations between suspended particulate matter and health has been reviewed in the United Kingdom report. ${ }^{11}$ There has not been recourse to the original data in the manner of the United States review, ${ }^{10}$ but the statistical methodology underlying most of the time-series (acute effects) studies has been considered to be appropriate and, in general, the way that confounding variables such as season and temperature have been dealt with has been satisfactory. One reservation on the latter point is whether these variables have been adequately specified. Temperature extremes, for example, are strongly associated with daily mortality and other health outcomes and the use of daily mean temperatures in reported studies may not bring out the full effect. However, the overall conclusion is that the studies, most of which come from the United States, present a consistent picture. Findings are expressed as regression relationships, indicating the percentage increase in health indicators for a given increase in particulate concentration. One example quoted is a $3.5 \%$ increase in hospital admissions for pneumonia associated with a $30 \mu \mathrm{g} / \mathrm{m}^{3}$ increase in $\mathrm{PM}_{10}$ in a study in Detroit. Applicability of findings from the USA and other countries has been considered. Among other factors are differences in the composition of suspended particulate matter, but within the USA similar results have been found in localities with different pollution mixes including the Utah Valley ${ }^{14}$ where the particles are from an industrial source rather than the usual urban mixture. This may argue for a nonspecific particle effect related more to physical than to chemical characteristics, and at this stage it has been considered prudent to treat findings from the international literature as being applicable to the United Kingdom.

The above remarks apply to the examination of associations between suspended particulate matter and acute effects on a day-to-day basis. There has also been a resurgence of interest in the effects of long term exposure to air pollutants with the emphasis on particles. Considerable differences in death rates and in the prevalence of respiratory disease occur between localities with differing pollution levels, but the difficulty in interpreting them in a cross-sectional manner is that other relevant factors such as smoking habits could also be different and there is usually little information on the historical exposures to pollution. The opportunity has now arisen in the USA to examine data from two prospective cohort studies within which information on smoking habits together with pollution data for at least the more recent years are available. ${ }^{1516}$ This aspect is considered in the UK report, ${ }^{11}$ but a more recent review appears in a paper by $\mathrm{Li}$ et al in this issue of Thorax. ${ }^{17}$

The information currently available from original papers and reviews - particularly on acute effects - has been used as a basis for recommending an air quality standard in terms of $\mathrm{PM}_{10}$, put forward recently ${ }^{18}$ as a 24 hour running average of $50 \mu \mathrm{g} / \mathrm{m}^{3}$, subject to review within five years in the light of new data. In particular there is a need for further epidemiological studies within the UK, for investigations on possible mechanisms, and for clearer guidance on the most appropriate measure of suspended particulate matter with respect to effects on health. Recent UK based epidemiological studies have included investigation of daily hospital admissions in Birmingham which showed a significant association of respiratory admissions with $\mathbf{P M}_{10}$ levels (unpublished observations) and an examination of the increased morbidity and. mortality that occurred in an air pollution episode in 1991, though the relative roles of particulate matter and of nitrogen dioxide could not be distinguished. ${ }^{19}$

New light has been shed on the physical and chemical characteristics of suspended particulate matter as observed in the UK today by the report of an investigation carried out for the Department of Health. ${ }^{20}$ This has comprised electron microscopic studies with information on composition for suspended particles in the air and for material found in lung tissue. The investigators found that almost all the airborne particulate matter encountered in urban air could be classified as $\mathbf{P M}_{10}$ and that vehicle exhaust, particularly from diesel engines, was a major source in urban areas. This exhaust material consisted of aggregates in sizes up to $4 \mu \mathrm{m}$, the individual component spheres having diameters of about $0.05 \mu \mathrm{m}$. Some of the $\mathbf{P M}_{10}$ material was soluble, comprising nitrates, chlorides and sulphates, these being derived in part, via atmospheric reactions, from general combustion sources. The examination of material recovered from lung tissue gave an indication of historical exposures to particulate matter. While the same types of sub-micron aggregates found in airborne samples were present, there were also larger individual particles. The aggregates with their larger surface areas were, however, considered to pose greater health risks then the individual particles.

The Quality of Urban Air Review Group has also produced a detailed report recently on the nature, sources, and measurement of particulate matter. ${ }^{21}$ Attention is drawn to the valuable series of measurements in terms of $\mathrm{PM}_{10}$ now being made using automatic monitors at urban sites in the $\mathrm{UK}$, and again emissions from motor traffic are seen to be a major source at such sites. There is a relatively uniform background of secondary particles across the country formed from gas to particle reactions involving emissions from large combustion plants in the UK and in continental Europe, and there are some locations (such as Belfast) where the domestic use of solid fuels contributes substantially, but it is considered that continued efforts are required to reduce emissions from motor vehicles in order to reduce airborne concentrations further, and particularly to avoid the peak values that occur in winter.

New studies continue to be reported from the USA. One recent contribution ${ }^{22}$ found an association between hospital admissions and $\mathrm{PM}_{10}$ levels in an area (Spokane) where sulphur dioxide, which often accompanies suspended particulate matter, was virtually absent. On the other hand, arguments have been put forward ${ }^{23}$ to support a case for the concentration of particulate sulphate, derived from sulphur dioxide through atmospheric reactions, to serve as an indicator of particulate matter when evaluating health risks. This does not necessarily imply that sulphate itself is the chemical component responsible for adverse effects of particulates. It could be serving as a proxy for particulate acid or for the fine component of particulate matter in general. There is much debate currently in the USA as to whether it would be more appropriate to monitor particles below $2.5 \mu \mathrm{m}$ in diameter $\left(\mathrm{PM}_{2.5}\right)$ than those below $10 \mu \mathrm{m}$.

Thus, despite the "new light" of a galaxy of studies indicating a role for even the modest concentrations of 
suspended particulates experienced today in exacerbations of respiratory illness, admissions to hospital, or increases in daily deaths, many aspects still require further elucidation.

Correspondence to: Dr R L Maynard.

Department of Health,

Skipton House,

80 London Road,

R L MAYNARD

London SE1 6LW, UK

1 Evelyn J. Fumifugium. 1661, reprinted 1961 by the National Society for Clean Air, London.

Waller RE. Control of air pollution: present success and future prospect. In: Bennett $\mathrm{AE}$, ed. Recent advances in community medicine. Volume 1. EdinBennett AE, ed. Recent advances in communt

3 Schwartz J, Marcus A. Mortality and air pollution in London: a time-series analysis. Am F Epidemiol 1990;131:185-94.

4 Pope CA, Dockery DW, Spengler JD, Raizenne ME. Respiratory health and $\mathrm{PM}_{10}$ pollution. A daily time-series analysis. Am Rev Respir Dis 1991;144 668-74.

Schwartz J. Air pollution and daily mortality. A review and meta-analysis. Environ Res 1994;64:36-52.

6 Schwartz J. Air pollution and hospital admissions for the elderly in Detroit, Michigan. Am f Respir Crit Care Med 1994;150:648-55.

7 Maynard RL. Air pollution: should we be concerned about it? f R Soc Med 1993;6:63-4.

8 World Health Organisation. Air quality guidelines for Europe. Regional Publication 23. Copenhagen: World Health Organisation, 1987.

9 World Health Organisation. Update and revision of the air quality guidelines for Europe. EUR/ICP/EHAZ 94 05/PBOI. Copenhagen: World Health Organisation, 1995.
10 Samet JM, Zegar SL, Berhane K. The association of mortality and particulate air pollution. Replication and validation of selected studies. Cambridge, MA: air pollution. Replication and valid

11 Department of Health. Committee on the Medical Effects of Air Pollutants. Non-biological particles and health. London: HMSO, 1995.

12 Department of Health. Advisory Group on the Medical Aspects of Air Pollution Episodes. Second Report. Sulphur dioxide, acid aerosols and parPollution Episodes. Second Rep

13 Oberdörster G, Ferin J, Gelein R, Soderkolm SC, Finkelstein J. Role of alveolar macrophage in lung injury studies with ultrafine particles. Environ

14 Pope CA, Dockery DW, Spengler JD, Raizenne ME. Respiratory health and $\mathrm{PM}_{10}$ pollution. A daily time-series analysis. Am Rev Respir Dis 1991;144:

15 Dockery DW, Pope CA, Xu X, Spengler JD, Ware JH, Fay ME, et al. An association between air pollution and mortality in six US cities. $N$ Engl $\mathcal{F}$ Med 1993;329:1753-9.

16 Pope CA, Thun MJ, Mamboodiri MM, Dockery DW, Evans JS, Speizer FE, et al. Particulate air pollution as a predictor of mortality in a prospective study of US adults. Am 7 Respir Crit Care Med 1995;151:669-74.

$17 \mathrm{Li} \mathrm{XY,} \mathrm{Gilmour} \mathrm{PS,} \mathrm{Donaldson} \mathrm{K,} \mathrm{MacNee} \mathrm{W.} \mathrm{Free} \mathrm{radical} \mathrm{activity} \mathrm{and} \mathrm{pro-}$ inflammatory effects of particulate air pollution $\left(\mathrm{PM}_{10}\right)$ in vivo and in vitro. Thorax 1996;51:1216-22.

18 Department of the Environment. Expert Panel on Air Quality Standards. Particles. London: HMSO, 1995.

19 Anderson HR, Limb ES, Bland JM, Ponce de Leon A, Strachan DP, Bower JS. Health effects of an air pollution episode in London, December 1991 Thorax 1995;50:1188-93. (Report commissioned by the Department of Health, UK, St George's Hospital Medical School, 1994.)

20 Pooley FD, Gibbs AR. Characterisation of fine particulate matter $\left(P M_{11}\right)$ in airborne samples and tissues. Final report to the Department of Health. University of Wales, Cardiff, 1996.

21 Quality of Urban Air Review Group. Third Report. Airborne particulate matter in the United Kingdom. London: Department of the Environment, 1996.

22 Schwartz J. Air pollution and hospital admissions for respiratory disease. Epidemiology 1996;7:20-8

23 Lippmann M, Thurston GD. Sulphate concentrations as an indicator of ambient particulate matter air pollution for health risk evaluation. $\mathcal{F}$ Expo Anal Environ Epidemiol 1996 (in press). 